\title{
Prevalence of Obstructive Sleep Apnea and Impact of Menopause on It among Women of Rural Area of Pakistan
}

\author{
Tayyab Mumtaz Khan, Madeeha Mumtaz, Maira Naseer, Sania Saher, Farwa Shabbir, \\ Munazzah Kaleem, Syeda Aimen Waris, Mubashira Kiran, Sana Mansoor, and Hina Mansoor
}

\section{ABSTRACT}

Obstructive sleep apnea (OSA) is a common sleep related disorder, and it is affected by number of factors including age, gender, obesity, educational status and menopause. However, in the presence of conflicting findings regarding impact of menopause on OSA, our study was aimed to check the prevalence of OSA in women and impact on it of menopause. This descriptive cross-sectional study was conducted in around 3months from August 2020 to October 2020 in a rural area of Punjab, Pakistan. 205 participants were recruited according to set criteria of our study. Women with age from above 30 years to 60 years, who had regular menstrual cycles or had cessation of menses since at least one last year were enrolled in the study whereas women who had irregular menstrual cycles and were not willing to participate were excluded from the study. Data was collected by two questionnaires including self-structured proforma and STOP Questionnaire. Data analysis was done with the help of SPSS version 25. Different tests including Chi-square test and Independent Sample t-test were applied to evaluate the study variables. In general, current study indicates high prevalence $(28.3 \%)$ of high risk of OSA among women, however, STOP score was higher among postmenopausal women (1.641 with $\mathrm{SD} \pm 0.908)$ as compared to premenopausal women $(1.073 \mathrm{SD} \pm 0.693)$ ) which means that postmenopausal women had higher risk of development of OSA in comparison with premenopausal women. The association between OSA risk and menopause was statistically significant $(p=0.001)$. The difference of score between premenopausal women and postmenopausal women was significant statistically $(p=0.0001)$. In short, prevalence of OSA high risk is higher among postmenopausal women in comparison with premenopausal women and menopause affects OSA but the mechanism is still not clear.

Keywords: Prevalence, Obstructive Sleep Apnea, Impact, Menopause, Women, Rural Area, Pakistan.

\section{INTRODUCTION}

One of the common sleep disorders is obstructive sleep apnea (OSA) and it remains undiagnosed for long time and even the whole life of a patient, that is why it gets little attention by patients and physicians. During sleep OSA is marked by repeated obstruction of upper airway and it is accompanied with intermittent hypoxia, fragmentation of sleep, increased sympathetic tone, and oxidative stress [1]. Long term effects of OSA includes increase in risk of cardiovascular and metabolic diseases. One of key symptoms of OSA is Excessive Daytime Sleepiness (EDS), and in this way OSA leads to poor quality of life and decline in cognition and consequently, reduction in productivity of individuals [2], [3]. In literature, different studies have reported that
Published Online: January 30, 2021 ISSN: 2593-8339

DOI: $10.24018 /$ ejmed.2021.3.1.683

\section{Tayyab Mumtaz Khan*}

Rawalpindi Medical University, Rawalpindi, Pakistan.

(e-mail: tayyab.mkhan98@ gmail.com) Madeeha Mumtaz

Lahore College for Women University, Pakistan.

Maira Naseer

Rawalpindi Medical University, Rawalpindi, Pakistan.

Sania Saher

University of Agriculture, Pakistan. Farwa Shabbir

Rawalpindi Medical University, Rawalpindi, Pakistan.

Munazzah Kaleem

Rawalpindi Medical University,

Rawalpindi, Pakistan.

Syeda Aimen Waris

Rawalpindi Medical University,

Rawalpindi, Pakistan.

Mubashira Kiran

Rawalpindi Medical University,

Rawalpindi, Pakistan.

Sana Mansoor

Rawalpindi Medical University,

Rawalpindi, Pakistan.

Hina Mansoor

National University of Modern

Languages, Pakistan.

*Corresponding Author patients, mortality increases in the presence of severe OSA as compared to moderate and mild OSA [4]. In literature, various factors have been reported to affect the risk of OSA including age, gender, obesity, educational status, and menopausal status. Different studies have shown that the risk of OSA is higher in men, older population and illiterate population as compared to women, younger population and educated population. Similarly, higher incidence of OSA among obese and women after menopause has been noted in different studies [5]-[7]. About the association of menopause and OSA risk different studies have conflicting findings, according to some studies menopause increases risk of OSA because it's a state where a lot of changes take place in the body of women, and that could be the reason of increase incidence of OSA after menopause. One of those important changes include lack of protective effects on upper airway of 
estrogen and progesterone [7]-[13]. Studies, in literature also show that menopause has no effect on the incidence of OSA and it is only because of aging associated comorbidities [14], [15]. So, this issue is yet present and need to be solved, that whether menopause affects or not the incidence of OSA. Although, around the globe various studies have been conducted to assess the impact of menopause on the incidence of obstructive sleep apnea [7], [16], [17]. However, in Pakistan very little knowledge is present on obstructive sleep apnea in literature and almost no study is present nationally and locally that could explain the effect of menopause on OSA. So, in the absence of study at national level, particularly at local level, and in the presence of studies at international level, with conflicting findings regarding menopause and OSA, our study aims to assess overall prevalence of OSA and the impact of menopause on the incidence of obstructive sleep apnea among women in rural area of (THQ) Tehsil Headquarter Hospital, Phalia, Punjab, Pakistan. If the results of our study indicate that menopause affects OSA and influences positively then by implementation of interventions and proper treatment of changes that occur in women after menopause, we would be able to bring improvement in quality of life and reduction in risk of other related diseases like of cardiovascular system and metabolism. Therefore, overall productivity of people could be increased and loads on hospitals could be decreased.

\section{MATERIALS AND METHODS}

\section{A. Study Design and Study Population}

This descriptive cross-sectional study was conducted at nearby rural area of (THQ) Tehsil Headquarter Hospital Phalia, Punjab, Pakistan on general Population of women in the duration of approximately 3 months from August 2020 to October 2020. 205 women were recruited in the study on the basis of exclusion and inclusion criteria i.e., women with age from above 30 years to 60 years, who had regular menstrual cycles or had cessation of menses since at least one last year were enrolled in the study whereas women who had irregular menstrual cycles and were not willing to participate were excluded from the study. Data collection was accomplished through two questionnaires including self-structured proforma and STOP scale for OSA. After proper elaboration of aim of study informed consent was taken from all recruited participants. Questionnaires were filled via interview of study population.

\section{B. Assessment of Demographic Details and Menopausal Status of Study Population}

A self-structured proforma was made to obtain information regarding the demographic components including age and menopause status. Based on the menopausal status of participants, they were divided into two premenopausal (who had regular menstrual bleeding) and postmenopausal (who had no menstrual bleeding from since last one year).

\section{Assessment of Obstructive Sleep Apnea}

We used STOP Questionnaire for the assessment of risk of OSA Obstructive Sleep. It has been used globally [5]. Although absolute form of this questionnaire is STOPBANG, nevertheless, we applied only STOP portion of it.
STOP composed of four questions ( $\mathrm{S}=$ do you Snore loudly?, $\mathrm{T}=$ do you often feel Tiredness or day time sleepiness?, $\mathrm{O}=$ have you Observed stop of breathing during sleep?, and $\mathrm{P}=$ have you or being treated for high blood Pressure). Answer of each of these questions could be $\mathrm{YES}=1$ or $\mathrm{NO}=0$. So overall score could vary from 0 to 4 . On the basis of score or yes or no, participants were split up into two groups. One group who had high risk and second group who had low risk for development of OSA. Women who had answered yes to two or more questions were regarded as high risk and women who had answered yes to only one or to none were regarded as low risk.

\section{Data Analysis}

A descriptive data analysis was accomplished by using SPSS version 25 of study variables. To check the reliability of STOP Questionnaire for Obstructive Sleep Apnea (OSA), a pilot study was carried out on 52 participants. Cronbach alpha value was calculated, and it was 0.723 indicating high reliability of STOP Questionnaire for OSA. Chi square analysis was used to evaluate the association between OSA risk and menopause. Difference in STOP score across the menopausal status was checked using Independent sample ttest. Then difference in STOP score between participants who had high risk and participants who had low risk for OSA was also assessed by Independent sample t-test. The value of $\mathrm{p}$ less than 0.05 was set statistically significant.

\section{RESULTS}

Our study population consisted of 205 women, and based on menopausal status of participants, $113(55.1 \%)$ women were at premenopausal stage of their lives while 92 (44.9\%) women were at postmenopausal stage of their lives.

Mean age of study population was 44.946 years with standard deviation (SD) of \pm 9.011 and mean score for study population on STOP scale for obstructive sleep apnea (OSA) was 1.34 with $\mathrm{SD}$ of \pm 0.840 .

Table I shows that $58(28.3 \%)$ women had higher risk of development of OSA while 147 (71.7\%) women had lower risk for development of OSA. Higher risk was more prevalent among postmenopausal women as compared to premenopausal women. Moreover, it also displays the parameters of study population together with their crosstabulation with study variables and chi-square analysis for evaluation of association between Menopause status and OSA. Association was statistically significant ( $\mathrm{p}=0.001)$.

Table II summarizes menopausal status-based variation in mean score on STOP scale for OSA (obstructive Sleep Apnea) together with results of independent sample t-test and this difference was significant $(\mathrm{p}=0.0001)$ statistically. Postmenopausal women had more mean score in comparison to premenopausal women, which means that they (Postmenopausal) had higher risk for OSA.

Table III indicates the difference in mean score on STOP scale between high risk women for OSA and low risk women for OSA. Significance of this difference was assessed by Independent Sample t-test and it was quite significant with $\mathrm{p}$ value of 0.0003 .

In general, we noticed high prevalence of OSA high risk participants, and our study suggests that menopause leads to 
increase in risk of obstructive sleep apnea among women that is why postmenopausal women had higher risk of obstructive sleep apnea as compared to premenopausal women who had lower risk of development of obstructive sleep apnea.

TABLE I: POPULATION PARAMETERS ALONG WITH THEIR CROSSTABULATION WITH STUDY VARIABLES AND CHI-SQUARE ANALYSIS Cross-Tabulation and chi-square analysis

\begin{tabular}{|c|c|c|c|c|}
\hline \multirow{2}{*}{\multicolumn{2}{|c|}{ Parameter }} & \multicolumn{2}{|c|}{ Obstructive Sleep Apnea Risk } & \multirow{2}{*}{$\begin{array}{c}\text { Chi- } \\
\text { Square } \\
\text { Analysis }\end{array}$} \\
\hline & & Higher Risk & Lower Risk & \\
\hline Tota & 205 & $\begin{array}{c}58 \\
(28.3 \%) \\
\end{array}$ & $\begin{array}{c}147 \\
(71.7 \%) \\
\end{array}$ & $\mathrm{p}$-value \\
\hline \multirow{2}{*}{$\begin{array}{l}\text { Menopausa } \\
1 \text { Status }\end{array}$} & $\begin{array}{c}\text { Premenop } \\
\text { ausal } \\
n=113\end{array}$ & $21(18.58 \%)$ & $\begin{array}{c}92 \\
(81.41 \%)\end{array}$ & \multirow{2}{*}{0.001} \\
\hline & $\begin{array}{c}\text { Postmeno } \\
\text { pausal } \\
n=92\end{array}$ & $\begin{array}{c}37 \\
(40.22 \%)\end{array}$ & $\begin{array}{c}55 \\
(59.78 \%)\end{array}$ & \\
\hline
\end{tabular}

TABLE II: DiFFERENCE IN STOP SCALE SCORE BASED ON MENOPAUSAL STATUS AND INDEPENDENT SAMPLE T-TEST ANALYSIS

\begin{tabular}{cccc}
\hline \multicolumn{3}{c}{ STATUS AND INDEPENDENT SAMPLE T-TEST ANALYSIS } \\
\cline { 3 - 4 } \multicolumn{2}{c}{ Parameter } & $\begin{array}{c}\text { STOP Scale } \\
\text { Score }\end{array}$ & $\begin{array}{c}\text { Independent } \\
\text { Sample t-test }\end{array}$ \\
\cline { 3 - 4 } & Mean $( \pm$ SD) & p-value \\
\hline $\begin{array}{c}\text { Menopausal } \\
\text { Status }\end{array}$ & $\begin{array}{c}\text { Premenopausal } \\
\text { Postmenopausal }\end{array}$ & $1.073( \pm 0.693)$ & 0.0001 \\
\hline
\end{tabular}

TABLE III: DIFFERENCE IN STOP SCALE SCORE BETWEEN LOW RISK AND HIGH RISK WOMEN AND RESULTS OF INDEPENDENT SAMPLE T-TEST

\begin{tabular}{cccc}
\multicolumn{3}{c}{ HIGH RISK WOMEN AND RESULTS OF INDEPENDENT SAMPLE T-TEST } \\
\hline \multicolumn{2}{c}{ Parameter } & STOP Scale Score & $\begin{array}{c}\text { Independent Sample } \\
\text { t-test }\end{array}$ \\
\cline { 3 - 4 } & Mean $( \pm$ SD $)$ & p-value \\
\hline $\begin{array}{c}\text { Obstructive } \\
\text { Sleep } \\
\text { Apnea } \\
\text { Risk }\end{array}$ & Low Risk & $0.898( \pm 0.345)$ & \\
High Risk & $2.465( \pm 0.654)$ & 0.0003 \\
\hline
\end{tabular}

\section{IV.DISCUSSION}

Obstructive sleep apnea not only affects quality of life adversely but also increases the risk of cardiovascular system and decreases productivity of individuals. The results of our current study add serviceable information about the impact of menopause on the incidence of obstructive sleep apnea (OSA) and prevalence of higher risk and lower risk of OSA among women of rural area of (THQ) Tehsil Headquarter Hospital, Phalia, Punjab, Pakistan. At the beginning of data analysis, first we assessed the prevalence of women with higher risk of OSA and then we checked its difference between premenopausal women, and postmenopausal women. We observed overall prevalence of women, who had higher risk of obstructive sleep apnea was $28.3 \%$. On further data analysis we noted that, prevalence of higher risk for OSA was higher among postmenopausal women (40.22\%) in comparison to premenopausal women (18.58\%). Similar finding that postmenopausal women had higher risk of development of OSA was also noticed in a study that was conducted at Toronto, Canada [7]. We applied Chi-square test, in the next step of data analysis, to evaluate the association of menopause with OSA, and we found that the relationship between menopause and OSA was statistically significant with $\mathrm{p}$ value of 0.001 . This significant association means that menopause affects the incidence of OSA among women. Studies that were conducted at United States of America also reported matching results that with onset of menopause, the incidence of OSA goes up among women [8],
[9]. However, a study has also reported that there was no association between OSA risk and menopause [14]. When, the OSA incidence goes up, it not only adversely affects the quality of life among postmenopausal women, but it also brings other serious consequences like cardiovascular diseases and metabolic disorders [3]. Although the mean score on STOP scale was higher among postmenopausal women (1.641 with SD of \pm 0.908$)$ ) as compared to premenopausal women (1.073 with SD of \pm 0.693$)$, nevertheless, we checked that either this difference in STOP score between premenopausal women and postmenopausal women is significant or not. For this we used Independent sample t-test and we observed that difference was significant with $p$ value of 0.0001 . Higher score on STOP scale among postmenopausal women again means that they had higher risk of development of OSA and similar findings are present in other researches worldwide [5], [7]. At the end of data analysis, we assessed the significance of difference in mean STOP score between women with higher OSA risk (STOP mean score $=2.465$ with $\mathrm{SD}$ of \pm 0.654 ) and women with lower OSA risk (STOP mean score $=0.898$ with SD of \pm 0.345 ) and it was accomplished with Independent sample ttest and it was quite significant $(\mathrm{p}=0.0003)$. Although our study has some limitations because of cross sectional design of it, however, our current study is first study in nearby rural area of (THQ) Tehsil Headquarter Hospital, Phalia, Punjab, Pakistan that highlights the impact of menopause on risk of obstructive sleep apnea and its prevalence among women. Health related authorities of this area must take serious measures into action that could treat or reduce the higher incidence of OSA among women after menopause. By treating OSA and reducing the incidence of OSA we could not only increase the quality of lives among postmenopausal but we could also reduce severe consequences that are linked with OSA like metabolic disorders and cardiovascular diseases. In literature, even though, various reasons have been given in different studies that have been conducted around the globe, for the higher risk of OSA among postmenopausal women, including aging related disorders, lack of protective effects of progesterone and difference in fat distribution in postmenopausal women [5], [8]-[13], [19]. Nevertheless, what are real causes of more prevalence of OSA risk in postmenopausal women is yet not clear. As far as we know, at national and local level very little knowledge is present about the factors that leads to increase in risk of OSA among postmenopausal women. So, further researches are required to get information regarding the factors that are the cause of higher incidence of OSA among women after menopause.

\section{CONCLUSION}

In general, our study indicates that high prevalence of higher risk of development of obstructive sleep apnea among women particularly among postmenopausal women as compared to premenopausal women. Postmenopausal women had high score on obstructive sleep apnea scale whereas premenopausal women had lower score on obstructive sleep apnea scale indicating that menopause leads to increase in risk of development of Obstructive sleep apnea. Proper preventive measures and treatments are required for women 
particularly for postmenopausal, so that in women obstructive sleep apnea could be prevented.

\section{ACKNOWLEDGMENT}

We (The principal author and the corresponding author Tayyab Mumtaz Khan and all co-authors) thank all respected individuals, who participated in this research.

\section{REFERENCES}

[1] Theorell-Haglöw J, Miller CB, Bartlett DJ, Yee BJ, Openshaw HD, Grunstein RR. Gender differences in obstructive sleep apnoea, insomnia and restless legs syndrome in adults-What do we know? A clinical update. Sleep Medicine Reviews. 2018 Apr 1;38:28-38.

[2] Shochat T, Pillar G. Sleep apnoea in the older adult. Drugs \& aging. 2003 Jul 1;20(8):551-60.

[3] Banno K, Kryger MH. Sleep apnea: clinical investigations in humans. Sleep medicine. 2007 Jun 1;8(4):400-26.

[4] Hongyo K, Ito N, Yamamoto K, Yasunobe Y, Takeda M, Oguro R, Takami Y, Takeya Y, Sugimoto K, Rakugi H. Factors associated with the severity of obstructive sleep apnea in older adults. Geriatrics \& Gerontology International. 2017 Apr;17(4):614-21.

[5] Foroughi M, Malekmohammad M, Sharafkhaneh A, Emami H, Adimi P, Khoundabi B. Prevalence of obstructive sleep apnea in a high-risk population using the stop-bang questionnaire in Tehran, Iran. Tanaffos. 2017;16(3):217.

[6] Schwartz AR, Patil SP, Laffan AM, Polotsky V, Schneider H, Smith PL. Obesity and obstructive sleep apnea: pathogenic mechanisms and therapeutic approaches. Proceedings of the American Thoracic Society. 2008 Feb 15;5(2):185-92.

[7] Dancey DR, Hanly PJ, Soong C, Lee B, Hoffstein V. Impact of menopause on the prevalence and severity of sleep apnea. Chest. 2001 Jul 1;120(1):151-5.

[8] Block AJ, Wynne JW, Boysen PG. Sleep-disordered breathing and nocturnal oxygen desaturation in postmenopausal women. The American journal of medicine. 1980 Jul 1;69(1):75-9.

[9] Block AJ, Wynne JW, Boysen PG, Lindsey S, Martin C, Cantor B. Menopause, medroxyprogesterone and breathing during sleep. The American journal of medicine. 1981 Mar 1;70(3):506-10.

[10] Antonijevic IA, Stalla GK, Steiger A. Modulation of the sleep electroencephalogram by estrogen replacement in postmenopausal women. American journal of obstetrics and gynecology. 2000 Feb $1 ; 182(2): 277-82$.

[11] Keefe DL, Watson R, Naftolin F. Hormone replacement therapy may alleviate sleep apnea in menopausal women: a pilot study. Menopause. 1999 Jan 1;6(3):196-200.

[12] Popovic RM, White DP. Upper airway muscle activity in normal women: influence of hormonal status. Journal of Applied Physiology. 1998 Mar 1;84(3):1055-62.

[13] Cistulli PA, Barnes DJ, Grunstein RR, Sullivan CE. Effect of shortterm hormone replacement in the treatment of obstructive sleep apnoea in postmenopausal women. Thorax. $1994 \mathrm{Jul}$ 1;49(7):699-702.

[14] Millman RP, Carlisle CC, McGarvey ST, Eveloff SE, Levinson PD. Body fat distribution and sleep apnea severity in women. Chest. 1995 Feb 1;107(2):362-6.

[15] Joffe H, Massler A, Sharkey KM. Evaluation and management of sleep disturbance during the menopause transition. InSeminars in reproductive medicine 2010 Sep (Vol. 28, No. 5, p. 404). NIH Public Access.

[16] Perger E, Mattaliano P, Lombardi C. Menopause and sleep apnea. Maturitas. 2019 Jun 1;124:35-8.

[17] Jehan S, Masters-Isarilov A, Idoko Salifu FZ, Jean-Louis G, PandiPerumal SR, Gupta R, Brzezinski A, McFarlane SI. Sleep disorders in postmenopausal women. Journal of sleep disorders \& therapy. 2015 Aug;4(5).

[18] Koo SK, Ahn GY, Choi JW, Kim YJ, Jung SH, Moon JS, Lee YI. Obstructive sleep apnea in postmenopausal women: a comparative study using drug induced sleep endoscopy. Brazilian journal of otorhinolaryngology. 2017 May 1;83(3):285-91.

[19] Carskadon MA, Bearpark HM, Sharkey KM, Millman RP, Rosenberg C, Cavallo A, Carlisle C, Acebo C. Effects of menopause and nasal occlusion on breathing during sleep. American journal of respiratory and critical care medicine. $1997 \mathrm{Jan} ; 155(1): 205-10$.

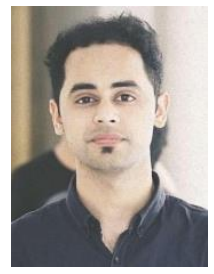

Tayyab Mumtaz Khan

Place of Birth: Lahore, Pakistan.

Date of Birth: $23^{\text {rd }}$ March 1996.

Educational Background: Final year MBBS student at Rawalpindi Medical University Rawalpindi, Pakistan. 